\title{
Drug Delivery in Asthmatic Children Following Coordinated and Uncoordinated Inhalation Maneuvers: A Randomized Crossover Trial
}

\author{
Ariel Berlinski, MD, Dirk von Hollen, BSc, Ross H.M. Hatley, PhD, \\ Lucy E.A. Hardaker, BSc (Hons), and Kurt Nikander, $\mathrm{PhD}^{4}$
}

\begin{abstract}
Background: Valved holding chambers (VHCs) are used in children to deliver pressurized metered dose inhalers (pMDI). In vitro data suggest that uncoordinated use decreases the amount of drug available for inhalation. We hypothesize that in an ex vivo study, the coordinated maneuver will deliver more drug than the uncoordinated one. Patients and Methods: Thirty-two clinically stable asthmatic children, ages 5-8 years, completed the study. An aerosol filter was interposed between a small-volume nonelectrostatic VHC and a mouthpiece to capture the drug emitted by one puff of Flovent ${ }^{\circledR} 220 \mathrm{mcg}$ during tidal breathing. Inhalation and actuation parameters were measured by an electronic monitor, and the number of breaths required to empty the VHC was calculated. Subjects completed three coordinated and three uncoordinated (actuation at the beginning of inhalation and exhalation, respectively) runs in random order. Drug content from the filter and VHC was measured by highperformance liquid chromatography and expressed as percentage of emitted dose.

Results: [mean (99\% confidence interval)] Filter dose was higher during coordinated technique 46\% (43\%$50 \%)$ than during uncoordinated technique $41 \%(37 \%-44 \%)(p<0.001)$. Peak inspiratory flow and tidal volume were $23.2 \mathrm{~L} / \mathrm{min}(21.3-25.1 \mathrm{~L} / \mathrm{min})$ and $281 \mathrm{~mL}(251-311 \mathrm{~mL})$, respectively. Subjects required three breaths to empty the VHC in $96 \%$ of the tests.

Conclusions: Actuating the pMDI into a small-volume nonelectrostatic VHC during exhalation reduced by $11 \%$ the amount of fluticasone captured at the exit of the VHC. Asthmatic children (5-8 years old) need three or less breaths to empty the small-volume VHC (NCT01714063).
\end{abstract}

Keywords: asthma, breathing pattern, fluticasone propionate, inhalation technique, valved holding chamber

\section{Introduction}

A STHMA IS THE MOST COMMON CHRONIC ILLNESS in childhood affecting $\sim 15 \%$ of the population. Inhaled corticosteroids are the cornerstone of the treatment of asthma and have been shown to be clinically safe in low and moderate doses. $^{(1)}$

The pressurized metered dose inhaler (pMDI) is used with a valved holding chamber (VHC) in pediatric patients.
Electrostatic charge of the plastic material used in some VHCs has been shown to reduce the amount of aerosol delivered. New VHCs are therefore mainly built of antistatic plastic materials that eliminate electrostatic charge. ${ }^{(2-5)}$ Caregivers and patients are instructed to breathe immediately after they actuate the pMDI. ${ }^{(5)}$ Improper inhalation technique has been associated to poor asthma stability. ${ }^{(6)}$ In vitro studies showed a decrease in drug output associated to actuation of the pMDI during exhalation. ${ }^{(7)}$ Therefore,

\footnotetext{
${ }^{1}$ Pulmonology Section, Department of Pediatrics, UAMS/COM, Pediatric Aerosol Research Laboratory, Little Rock, Arkansas.

${ }^{2}$ Respironics, Inc., a Philips Healthcare Company, Murrysville, Pennsylvania.

${ }^{3}$ Respironics Respiratory Drug Delivery (UK) Ltd, a Business of Philips Electronics UK Ltd, Chichester, United Kingdom.

${ }^{4}$ InDevCo AB, Nyköping, Sweden.

Partial data were presented by Dr. Berlinski at American Thoracic Society 2015 International Meeting (May 15-20, 2015, Denver, Colorado).

(C) Ariel Berlinski, et al., 2017. Published by Mary Ann Liebert, Inc. This Open Access article is distributed under the terms of the Creative Commons Attribution Noncommercial License (http://creativecommons.org/licenses/by-nc/4.0). which permits any noncommercial use, distribution, and reproduction in any medium, provided the original author(s) and the source are credited.
} 
knowing the variation of inhaled dose resulting from proper or improper technique is clinically relevant.

The amount of aerosol delivered through different pMDIVHC combinations can be determined in both in vitro and ex vivo filter studies. ${ }^{(8,9)}$ In an ex vivo filter study, the subject uses the pMDI-VHC combination as per the manufacturer's instructions, but the drug is deposited onto a filter interposed between the VHC mouthpiece and the subject's mouth. ${ }^{(8)}$ The amount of drug deposited on the filter represents the amount of drug available for inhalation.

The objective of this study was to compare the amount of fluticasone propionate (fluticasone) delivered via pMDIVHC combination in asthmatic children 5-8 years old, when using a coordinated or an uncoordinated technique. We hypothesized that using a coordinated technique would significantly increase drug delivery.

\section{Patients and Methods}

The study was performed at Arkansas Children's Hospital; it was approved by the University of Arkansas Institutional Review Board (\# 137456) and was registered at clinicaltrials.gov (NCT01714063). Parents provided written consent and subjects 7 years or older provided written assent. All the study-related procedures were done by the principal investigator (A.B.).

The inclusion criteria were (1) age 5-8 years followed at Arkansas Children's Hospital, (2) asthma diagnosis, clinically stable at time of enrollment, (3) prescribed an inhaled corticosteroid via pMDI-VHC combination, (4) previously used a VHC with mouthpiece or be able to use it, and 5) able to complete the study protocol.

The exclusion criteria were (1) inability to understand instructions, (2) participation in other clinical trials in the past 4 weeks, and (3) history of clinically significant respiratory disease during the 4 weeks before the study.

The study was designed as randomized, single-blind, crossover trial with parents and subjects unaware of the timing of the actuation of the pMDI. The study consisted of a single session without follow-up. The study was designed to recruit up to 40 subjects with the goal of having 16 subjects who completed the study in each of the age groups: 5-6.5 years (group 1) and 6.6-8 years (group 2). The following information was recorded: age, height, weight, gender, ethnicity, and number of years using VHC and mouthpiece. A CONSORT flowchart can be found in Figure 1.

The pMDI used was fluticasone (Flovent HFA $220 \mu \mathrm{g} / \mathrm{ac}-$ tuation; GSK, Research Triangle Park, NC). The VHC used was OptiChamber Diamond (Respironics Respiratory Drug Delivery Limited UK, Chichester, United Kingdom). ${ }^{(10)}$ The small volume $(145 \mathrm{~mL}) \mathrm{VHC}$ is made of transparent nonelectrostatic plastic material and has a low-resistance inspiratory valve within the mouthpiece, and a low-resistance expiratory valve placed on top of the mouthpiece assembly (Fig. 2). The plastic boot of the pMDI was modified to allow the connection of a data logger developed by Respironics (Fig. 3). ${ }^{(1)}$ The data logger had an accelerometer to detect the shaking of the pMDI, an ultrasonic detector to monitor the actuation of the pMDI, and a flow sensor to record the subject's inhalation profile (Fig. 3). The sensors were wired to an electronics enclosure where the signals were converted for communication to a personal computer. ${ }^{(11)}$
The study comprised eight measurements and each used a new VHC and filter. The first and the last measurements were carried out for quality control purposes using a vacuum source and did not involve the subject. Measurements 2 to 7 comprised three coordinated and three uncoordinated maneuvers with the subject. During coordinated and uncoordinated maneuvers, the investigator actuated the pMDI at the beginning of the inhalation and at the beginning of the exhalation, respectively. The order of these maneuvers was predetermined by a computer-generated randomization in block.

A new pMDI of fluticasone was used with each subject and was primed with four actuations to waste. A VHC was connected to a low dead space filter holder with a disposable filter media (Filtrete G-200; 3M, St. Paul, MN). The filter captures $99.3 \%$ of the fluticasone aerosol that is delivered to it, therefore minimizing subject exposure. At the beginning of the test, a volume calibration and sensor verification of the data logger were performed. The filter holder-VHCpMDI was connected to a suction pump $(30 \mathrm{~L} / \mathrm{min})$ and was actuated 10 times allowing 5 seconds of shaking before actuation and 30 seconds of interval between actuations.

Next, a new mouthpiece-filter-VHC was connected to the pMDI with data logger through the posterior opening of the VHC. The pMDI was then shaken and the subject was instructed to put the mouthpiece in his/her mouth, create a seal with his/her lips, and breathe tidally. The investigator monitored the subject's chest movement and the closing of the exhalation valve to determine the respiratory time (inhalation vs. exhalation). The investigator actuated the pMDI either in a coordinated or uncoordinated maneuver according to the randomization schedule and the subject was instructed to perform three tidal breaths. Five more tests were carried out with each subject and the second quality control measurement test was carried out. Samples were individually packaged and shipped to the Respironics laboratory in the United Kingdom, where drug analysis was performed using a validated high-pressure liquid chromatography method according to industry standards. The laboratory was blinded to all trial information.

The principal investigator (A.B.) kept the sponsor blinded to the identity of the subjects and once the data logger analysis and the biochemical analysis were completed, he provided the key to connect both data sets. The primary outcome was the amount of fluticasone captured in the filter (filter dose). Under current regulations, pMDIs are allowed to deliver a range between $85 \%$ and $115 \%$ of the nominal dose. $^{(12)}$ Therefore, differences smaller than $15 \%$ are unlikely to be clinically meaningful. In an attempt to normalize the data, we expressed the amount of fluticasone captured in the filter as the percentage of the delivered drug (filter $+\mathrm{VHC}$ ). Raw data from the data logger were processed to remove noise from the signal. Peak inspiratory flow and tidal volume for the three breaths that occurred after the actuation were determined and the number of breaths required to empty the VHC were calculated. ${ }^{(1)}$ Figure 4 shows an example of the data logger output for a coordinated and uncoordinated maneuver. All these variables were reported as mean and $99 \%$ confidence interval (CI).

We used a paired $T$-test for statistical analysis to compare the filter dose. Using the $1 \%$ significance level and assuming a between-subject standard deviation of $60 \mu \mathrm{g}$ (27\%) for the difference between coordinated and uncoordinated filter 


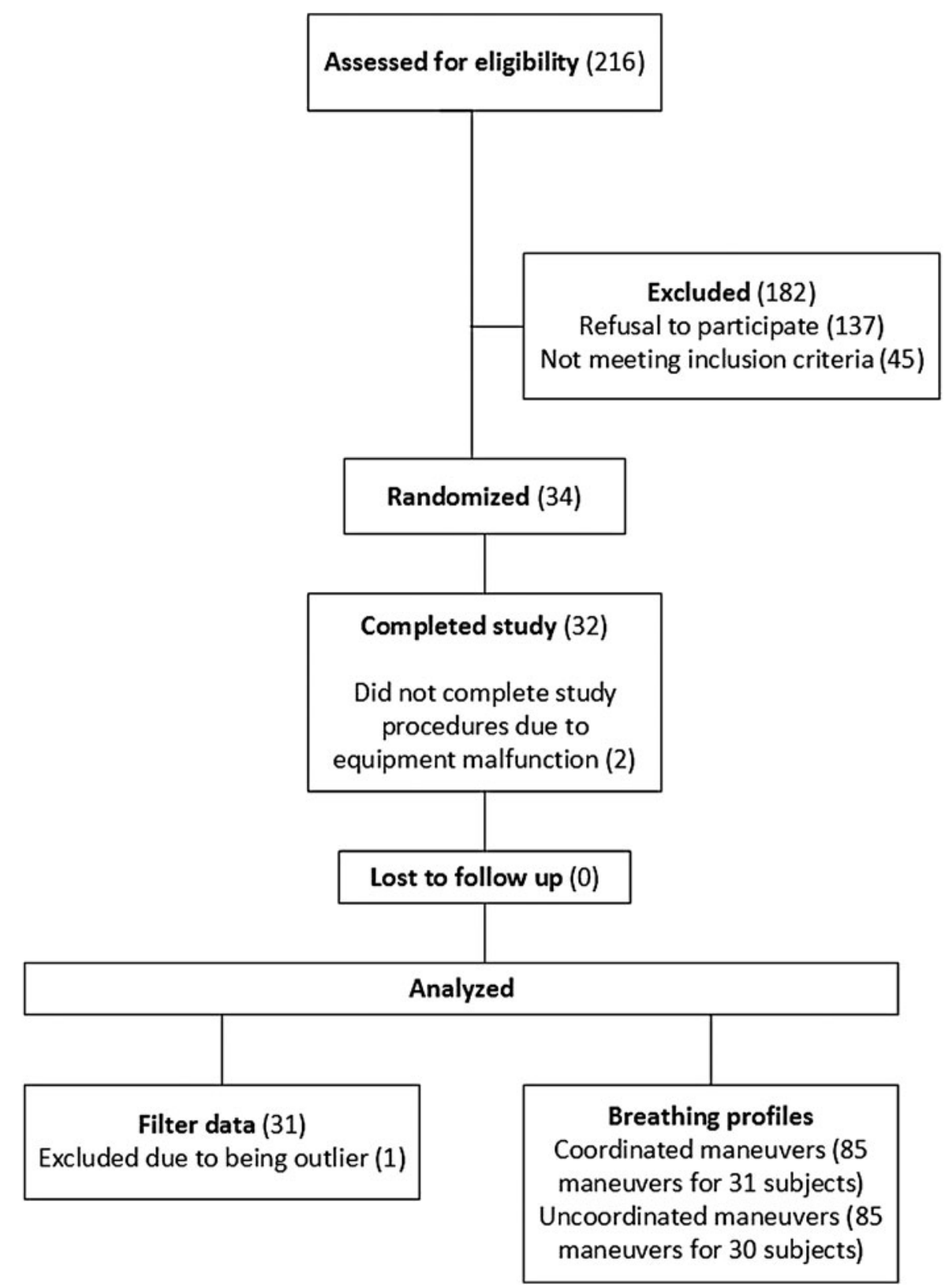

FIG. 1. CONSORT flowchart.

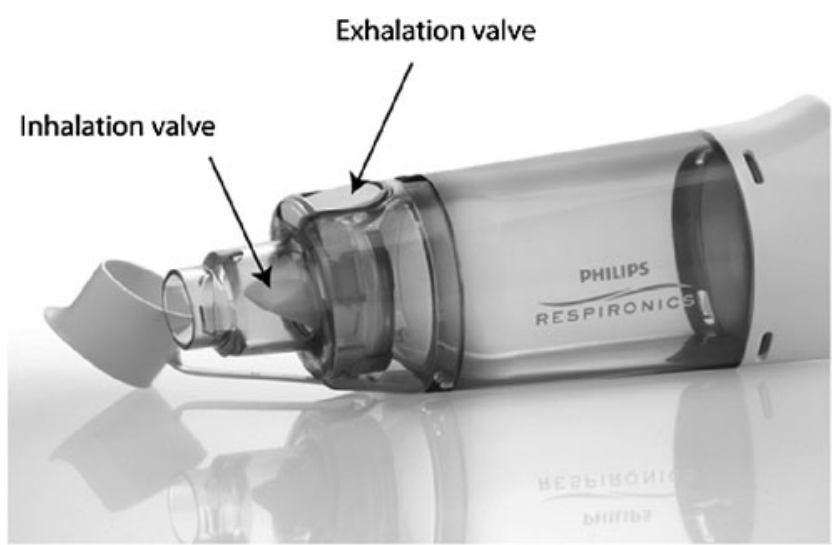

FIG. 2. Optichamber diamond. doses, 32 subjects are sufficient to detect a $45 \mu \mathrm{g}(20 \%)$ difference with $95 \%$ confidence. Grub's test with a significance level $<0.01$ was used to detect the presence of outliers. We used unpaired $T$-test to compare baseline characteristics between the two age groups. The MannWhitney test was used to compare the number of years the subjects used a VHC. Chi-square statistics was used to compare the proportion of subjects that was Caucasian and the proportion of subjects with mouthpiece experience. The significance level was established at 0.05 .

\section{Results}

\section{Subject flow}

Subjects were recruited between September 26, 2013, and May 1, 2014. A subject flow chart can be seen in Figure 1. 

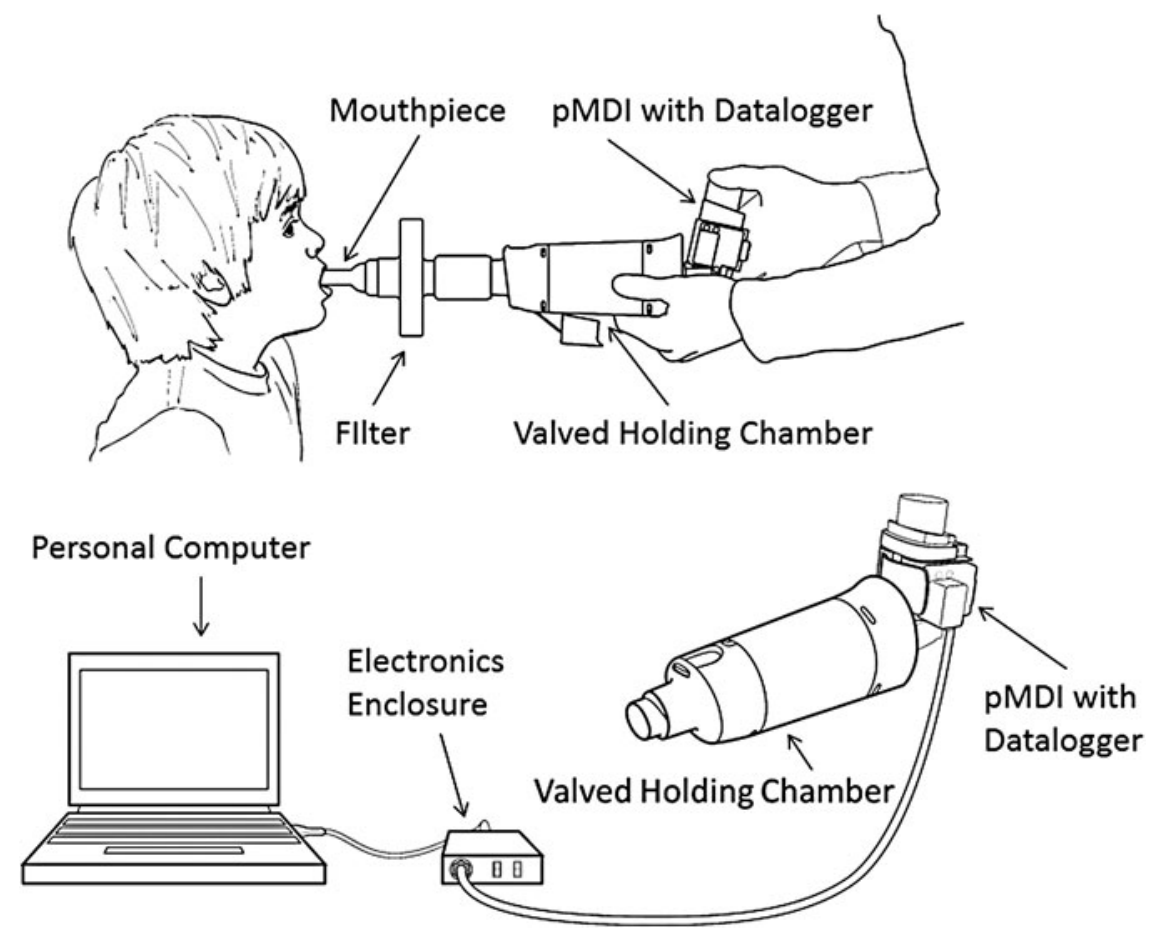

FIG. 3. Investigational setup with pressurized metered dose inhaler (pMDI) Data logger.

Subjects in group 1 were younger, and had less experience using a mouthpiece than subjects in group 2 (Table 1). However, all the subjects had minimal experience presenting a median $(95 \% \mathrm{CI})$ of $0(0-0.5)$ years of mouthpiece experience.

\section{Filter data}

The mean $(99 \% \mathrm{CI})$ filter dose was higher during coordinated technique $46 \%(43 \%-50 \%)$ than during uncoordinated technique $41 \%(37 \%-44 \%)(p<0.001)$ (Fig. 5). The difference remained statistically significant for both the older $45 \%(39 \%-51 \%)$ versus $40 \%(35 \%-45 \%)$ for coordinated and uncoordinated techniques, respectively, $p<0.001)$ and the younger groups $48 \%(44 \%-52 \%)$ versus $41 \%(36 \%-47 \%)$ for coordinated and uncoordinated techniques, respectively, $p<0.001)$.

\section{Breathing profile data}

Breathing profiles were similar among the three breaths that occurred after the actuation of the pMDI ( $p=0.65$ and $p=0.05$ for peak inspiratory flow during coordinated and uncoordinated maneuvers; and $p=0.94$ and $p=0.78$ for tidal volume during coordinated and uncoordinated maneuvers) (Table 2). Both peak inspiratory flow and tidal volume were similar between coordinated and uncoordinated maneuvers. This was true for when either the three breaths that occurred after the actuation of the pMDI ( $p=0.05$ and $p=0.09$ for inspiratory peak flow and tidal volume, respectively) or the first breath only was analyzed ( $p=0.16$ and $p=0.81$ for inspiratory peak flow and tidal volume, respectively).

The mean (99\% CI) peak inspiratory flow and tidal volume for all subjects were $23.2 \mathrm{~L} / \mathrm{min}(21.3-25.1 \mathrm{~L} / \mathrm{min})$ and $281 \mathrm{~mL}$ (251-311 mL), respectively.
The subjects required three, two, or one breath to empty the VHC in $96 \%(163 / 170), 93 \%(158 / 170)$, and $83 \%$ (141/ 170) of the maneuvers, respectively.

No adverse events occurred during the trial.

\section{Discussion}

Asthmatic children aged 5-8 years, with little mouthpiece experience, showed a statistically but unlikely to be clinically significant difference in the percentage of emitted dose of fluticasone captured in a filter, located at the exit of a VHC, between coordinated and uncoordinated inhalation maneuvers when using a small-volume, nonelectrostatic VHC with tidal breathing inhalation. The volume of the VHC was emptied by almost all subjects in three breaths or less.

The negative impact on the amount of drug available for inhalation resulting from actuating the pMDI at the beginning of the exhalation was smaller than expected. Foss and Keppel reported a $46 \%$ decrease in drug output from a small-volume VHC when the inhalation technique was changed from coordinated to uncoordinated. ${ }^{(7)}$ The difference could be explained, in part, by the fact that the VHC used in this study was made of a nonelectrostatic material, but that used by Foss was not. ${ }^{(2-4)}$ This is consistent with the findings of Pierart et al. who reported a 3.9-fold difference in intrapulmonary deposition of a radiolabeled aerosol when the electrostatic charge of a spacer was reduced by prewashing it with household detergent. ${ }^{(4)}$

The same group showed in an in vitro study, a $37.4 \%$ increase in drug output when the spacer was prewashed, thus reducing its electrostatic charge. ${ }^{(4)}$ Also, Wildhaber et al., in an in vitro study, showed that a delay between actuation and inhalation significantly reduced drug output in the untreated spacer but not in the one with reduced static charge. ${ }^{(13)}$ Although the reduction in filter dose that occurred between coordinated (46\%) 

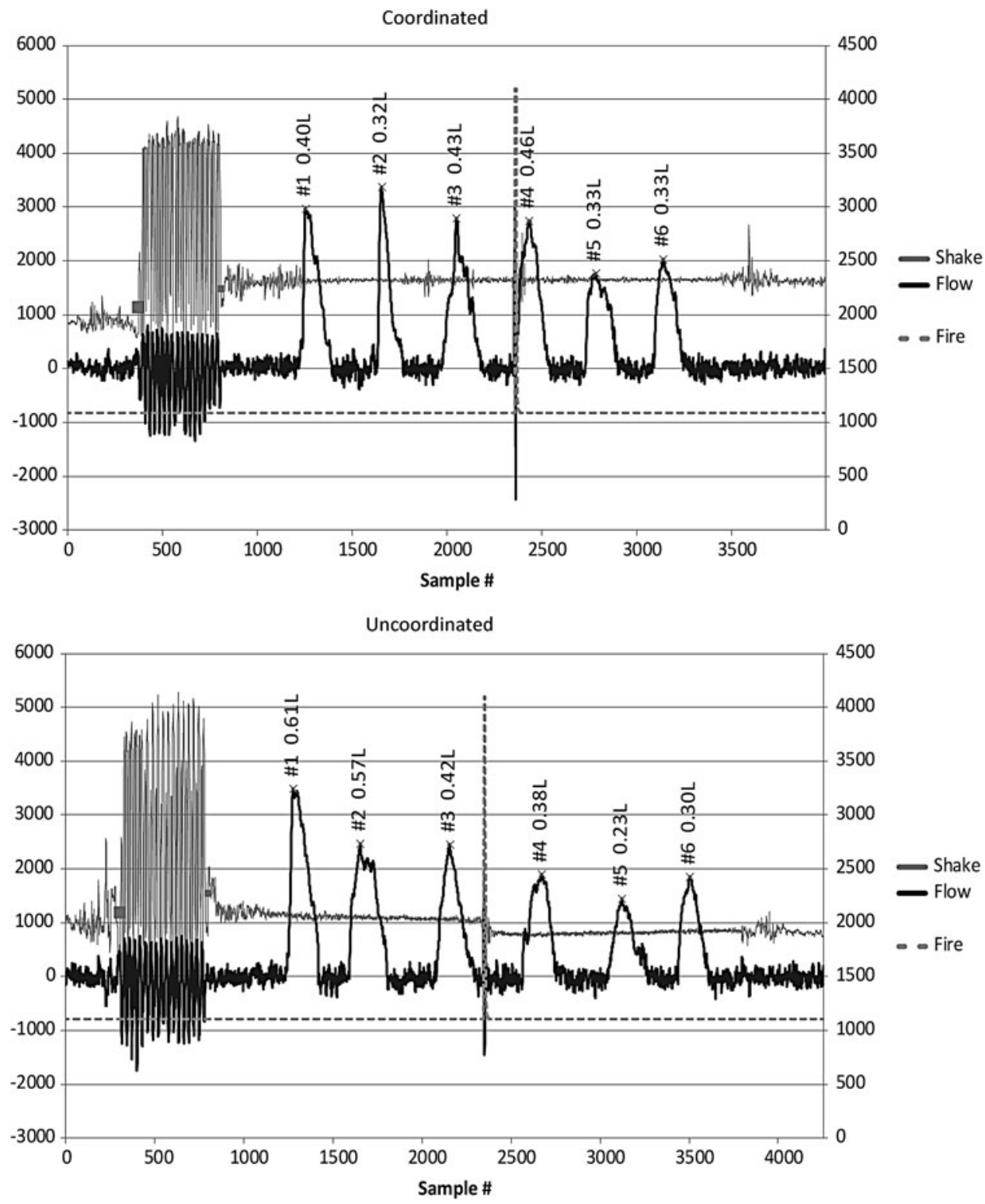

FIG. 4. Output from Data logger for a coordinated and uncoordinated maneuver.

and uncoordinated $(41 \%)$ maneuvers was statistically significant, it is unlikely to be clinically relevant. ${ }^{(12)}$

The recorded tidal volumes averaged $10-11 \mathrm{~mL} / \mathrm{kg}$, which is larger than typically expected for this age group. However, this is consistent with previous studies that show larger than ex- pected tidal volumes during inhalation through VHCs. ${ }^{(11,14)}$ Nonetheless, the average tidal volume recorded in this study was smaller than in other studies ( 281 vs. $400 \mathrm{~mL})$. The differences could be attributed to the fact that our population was older and therefore able to better follow instructions.

Table 1. Demographics

\begin{tabular}{|c|c|c|c|c|}
\hline & All & $5-6.5$ years & $6.6-8$ years & $\mathrm{p}$ \\
\hline No. of subjects & 32 & 16 & 16 & 0.99 \\
\hline Age, mean (SD), years & $6.4(0.8)$ & $5.7(0.4)$ & $7.1(0.4)$ & $<0.0001$ \\
\hline Male, $n(\%)$ & $20(63)$ & $8(50)$ & $12(75)$ & 0.27 \\
\hline Caucasian, $n(\%)$ & $17(53)$ & $10(63)$ & $7(44)$ & 0.49 \\
\hline Height, mean (SD), $\mathrm{cm}$ & $119.3(7.7)$ & $115.1(6.2)$ & $123.4(6.9)$ & 0.001 \\
\hline Weight, mean (SD), kg & $26.4(8.6)$ & $24.7(8.8)$ & $28(8.4)$ & 0.28 \\
\hline VHC experience, median $(95 \% \mathrm{CI})$, years & $3(2.5-4)$ & $3(2.5-4)$ & $3.5(2-5)$ & 0.93 \\
\hline Previous mouthpiece experience, $n(\%)$ & $13(41)$ & $2(13)$ & $11(69)$ & 0.003 \\
\hline
\end{tabular}

$p$-Values that are in bold font are statistically significant.

$\mathrm{CI}$, confidence interval; VHC, valved holding chamber. 


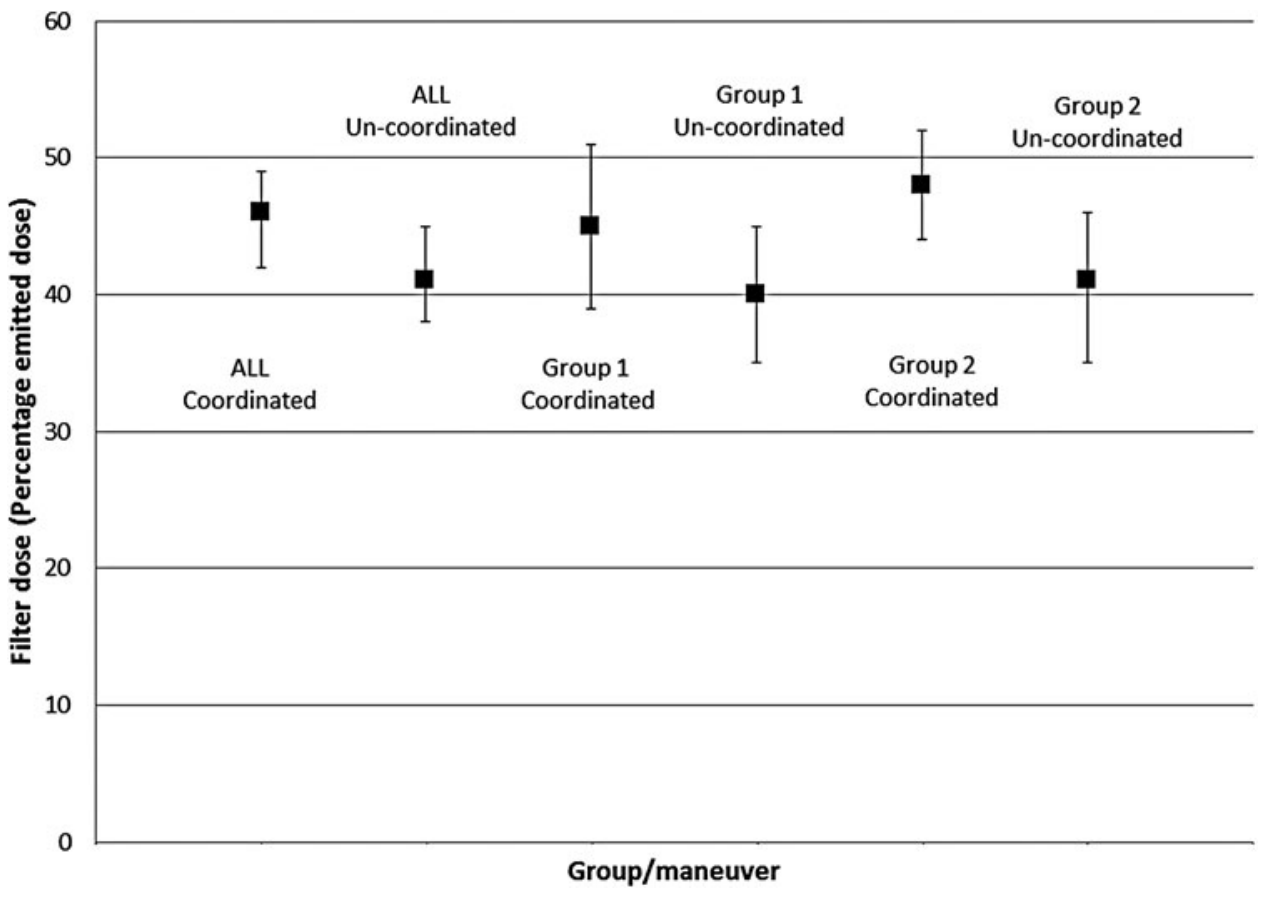

FIG. 5. Filter dose during coordinated and uncoordinated maneuvers.

The finding that two to three tidal breaths are sufficient to empty a small-volume VHC is consistent with the previous report by Schultz et al. ${ }^{(14)}$ In their study, they recorded the breathing pattern through a device of similar size and shape and then used the breathing patterns for in vitro evaluation. Our study incorporated a real-life factor by recording the tidal breathing pattern during the actual drug delivery with concomitant capture of drug available for oral inhalation (filter dose). The findings of both studies should be considered when planning future educational asthma activities.

Our findings have several important clinical implications. First, 5-8-year-old children with little to no experience of using a VHC with mouthpiece can successfully use it after minimal instruction. This is important because previous studies reported that the addition of dead space that occurs when a facemask is added to a VHC results in a decrease in the amount of drug available for oral inhalation. ${ }^{(15)}$ Also, the use of a mouthpiece avoids any facial, and potentially ocular, exposure that occurs with a facemask. ${ }^{(16)}$ Traditionally, the use of mouthpiece has been associated with the performance of a single-breath inhalation maneuver. In our study, we successfully used tidal breathing (three breaths) following the actuation of the inhaler. Patients should be changed from the $\mathrm{VHC} /$ facemask to $\mathrm{VHC} /$ mouthpiece once they are able to seal their mouths around the mouthpiece even if they are still not able to perform a single inhalation maneuver.

Second, 5-8-year-old children require only two to three breaths to empty the VHC. A lower number of required breaths than previously suggested could potentially enhance adherence to therapy by reducing the treatment burden.

Finally, our data suggest that in the age group studied while using a small-volume nonelectrostatic VHC, OptiChamber

Table 2. Breathing Profiles Obtained During Inhalation of a Pressurized Metered Dose Inhaler Through a Valved Holding Chamber

\begin{tabular}{llcr}
\hline & Breath & Coordinated maneuver & Uncoordinated maneuver \\
\hline Peak inspiratory flow, L/min & First & $25.2(20.5-30)$ & $22.8(17.6-28.1)$ \\
Peak inspiratory flow, L/min & Second & $23.3(18.5-28.1)$ & $22(17.3-26.6)$ \\
Peak inspiratory flow, L/min & Third & $23.2(18.3-28)$ & $22.5(17.1-27.9)$ \\
Peak inspiratory flow, L/min & All & $23.9(21.3-26.5)^{\mathrm{a}}$ & $22.4(19.6-25.2)^{\mathrm{a}}$ \\
Peak inspiratory flow, L/min & All & & $23.2(21.3-25.1)$ \\
Tidal volume, mL & First & $286(209-363)$ & $269(212-362)$ \\
Tidal volume, mL & Second & $281(215-363)$ & $259(186-333)$ \\
Tidal volume, mL & Third & $302(227-378)$ & $266(201-331)$ \\
Tidal volume, $\mathrm{mL}$ & All & $291(250-332) \&$ & $271(228-314)^{\mathrm{b}}$ \\
Tidal volume, $\mathrm{mL}$ & All & & $281(251-311)$ \\
\hline
\end{tabular}

Data are expressed as mean $(99 \% \mathrm{CI})$.

${ }_{\mathrm{b}}^{\mathrm{a}} p=0.053$ between coordinated and uncoordinated maneuvers.

${ }^{\mathrm{b}} p=0.09$ between coordinated and uncoordinated maneuvers. 
Diamond, the use of uncoordinated inhalation maneuver should not have significant consequences on drug delivery that could translate in loss of control of their asthma. Practitioners should be aware that if in a real-life situation patients are not responding to the prescribed therapy, every effort should be made to assure that the patients have a correct inhalation technique.

The study has some limitations: first, we did not measure particle size of the fluticasone aerosol. Second, we measured the drug available for inhalation but not the amount actually inhaled by the subjects. Moreover, we did neither measure lung deposition nor pharmacokinetics of the inhaled. These methods require the use of radio-labeled aerosols and frequent blood draws making them difficult to complete in children. Third, these findings should be limited to the studied age group and to a situation of clinical stability. Finally, all inhalation maneuvers were supervised by the investigators, and therefore, the reported differences could clinically be significant under real-life conditions. Future studies should include younger and older children and should be studied during an asthma exacerbation and after they have recovered.

\section{Conclusion}

In summary, 5-8-year-old asthmatic children with minimal mouthpiece experience are able to effectively use a small-volume VHC made of nonelectrostatic material with mouthpiece and require two to three breaths to empty its volume. Under these conditions, the use of an uncoordinated inhalation technique leads to a small reduction in the amount of drug available for oral inhalation.

\section{Acknowledgment}

This was an investigator-initiated study supported, in part, by Respironics, Inc., a Philips Healthcare company.

\section{Authors' Contributions}

All authors approved the final manuscript as submitted. A.B. conceptualized and designed the study, performed all patient-related study procedures, carried out the initial data analysis, drafted the initial manuscript, and revised it. D.v.H. designed the study, developed the data logger, standard operating procedures for transporting and analyzing samples, carried out the initial data analysis, and critically reviewed the initial draft. R.H. designed the study, developed the standard operating procedures for transporting and analyzing samples, carried out the initial data analysis, and critically reviewed the initial draft. L.H. developed the standard operating procedures for transporting and analyzing samples, and critically reviewed the initial draft. K.N. designed the study and critically reviewed the initial draft.

\section{Author Disclosure Statement}

A.B. served as Principal Investigator in clinical trials sponsored by Vertex, AbbVie, Allergan, Genentech, Janssen, Gilead, Teva, Philips, Novartis, National Institutes of Health, and Therapeutic Development Network. A.B. is a Science Advisor to the Device Human Factors Subgroup of the International Pharmaceutical Aerosol Consortium on Regulation and Science (IPAC-RS). The Pediatric Aerosol Research Laboratory at Arkansas Children's Hospital Research Institute was partially established and receives partial support from the George Endowment for Asthma. R.H. and L.H. are employees of Respironics Respiratory Drug Delivery UK Limited, Chichester, United Kingdom. D.v.H. is an employee of Respironics, Inc., a Philips Healthcare company, Murrysville, PA. K.N. was an employee of Respironics, Inc., a Philips Healthcare company, Parsippany, NJ, during part of the study.

\section{References}

1. From the Global Strategy for Asthma Management and Prevention, Global Initiative for Asthma (GINA) 2015. Available at: http://www.ginasthma.org. Accessed August $12,2015$.

2. Nikander K, Nicholls C, Denyer J, and Pritchard J: The evolution of spacers and valved holding chambers. J Aerosol Med Pulm Drug Deliv. 2014;27(Suppl 1):S4S23.

3. Newman S: Pressurized metered dose inhalers. In: S Newman (ed). Respiratory Drug Delivery: The Essential Theory and Practice. Respiratory Drug Delivery Online, Richmond, VA; pp. 177-216, 2009.

4. Pierart F, Wildhaber JH, Vrancken I, Devadason SG, and Le Souef PN: Washing plastic spacers in household detergent reduces electrostatic charge and greatly improves delivery. Eur Respir J 1999;13:673-678.

5. Laube BL, Janssens HM, de Jongh FH, Devadason SG, Dhand R, Diot P, Everard ML, Horvath I, Navalesi P, Voshaar T, and Chrystyn H; European Respiratory Society; International Society for Aerosols in Medicine: What the pulmonary specialist should know about the new inhalation therapies. Eur Respir J 2011;37:13081331.

6. Giraud V, and Roche N: Misuse of corticosteroid metereddose inhaler is associated with decreased asthma stability. Eur Respir J 2002;19:246-251.

7. Foss SA, and Keppel JW: In vitro testing of MDI spacers: A technique for measuring respirable dose output with actuation in-phase or out-of-phase with inhalation. Respir Care 1999;44:1474-1485.

8. Agertoft L, Pedersen S, and Nikander K: Drug delivery from the Turbuhaler and Nebuhaler pressurized metered dose inhaler to various age groups of children with asthma. J Aerosol Med 1999;3:161-169.

9. Berg E, Madsen J, and Bisgaard $\mathrm{H}$ : In vitro performance of three combinations of spacers and pressurized metered dose inhalers for treatment in children. Eur Respir J 1998;12: 472-476.

10. Hatley RH, von Hollen D, Sandell D, and Slator L: In vitro characterization of the OptiChamber Diamond valved holding chamber. J Aerosol Med Pulm Drug Deliv 2014;27 (Suppl 1):S24-S36.

11. Ditcham W, Murdzoska J, Zhang G, Roller C, von Hollen D, Nikander K, and Devadason SG: Lung deposition of 99mTc-radiolabeled albuterol delivered through a pressurized metered dose inhaler and spacer with facemask or mouthpiece in children with asthma. J Aerosol Med Pulm Drug Deliv 2014;27 (Suppl 1):S63-S75.

12. U.S. Department of Health and Human Services Food and Drug Administration. Center for Drug Evaluation and 
Research (CDER): Guidance for Industry. Metered Dose Inhaler (MDI) and Dry Powder Inhaler (DPI) Drug. Products. Chemistry, Manufacturing, and Controls Documentation. Rockville, MD; 1998.

13. Wildhaber JH, Devadason SG, Eber E, Hayden MJ, Everard ML, Summers QA, and LeSouëf PN: Effect of electrostatic charge, flow, delay and multiple actuations on the in vitro delivery of salbutamol from different small volume spacers for infants. Thorax 1996;51:985-988.

14. Schultz A, Le Souëf TJ, Venter A, Zhang G, Devadason SG, and Le Souëf PN: Aerosol inhalation from spacers and valved holding chambers requires few tidal breaths for children. Pediatrics 2010;126:e1493e1498.

15. Chavez A, McCracken A, and Berlinski A: Effect of face mask dead volume, respiratory rate, and tidal volume on inhaled albuterol delivery. Pediatr Pulmonol 2010;45:224229.

16. Geller DE: Clinical side effects during aerosol therapy: Cutaneous and ocular effects. J Aerosol Med 2007;20 (Suppl 1):S100-S108; discussion S109.
Received on August 4, 2016 in final form, November 2, 2016

Reviewed by: Israel Amirav Wolfgang Kamin

Address correspondence to: Ariel Berlinski, MD

Pulmonology Section Department of Pediatrics UAMS/COM

Pediatric Aerosol Research Laboratory ACRI

1 Children's Way

Slot 512-17

Little Rock, AR 72202

E-mail: berlinskiariel@uams.edu 